\title{
A Case of Dermatofibroma of the Upper Lip
}

\author{
Hye In Lee, M.D., Jin Woong Lee, M.D., Tae Young Han, M.D., Kapsok Li, M.D., \\ Chang Kwun Hong, M.D., Seong Jun Seo, M.D., Kye Yong Song, M.D. ${ }^{1}$ \\ Departments of Dermatology and ${ }^{1}$ Pathology, College of Medicine, Chung-Ang University, Seoul, Korea
}

\begin{abstract}
Dermatofibroma (DF) is a common benign mesenchymal tumor composed of fibroblastic and histiocytic cells. It occurs anywhere on the body surface but has a propensity for the extremities. To our knowledge, DF arising in the oral cavity, especially on the lip, is quite rare. DFs of the head and neck region have been known to be most often of the cellular type and frequently recur, so a wider initial excision is recommended. Herein we report a case of DF in a 41-year-old female who presented with a deep-seated nodule on her upper lip. (Ann Dermatol 22(3) 333 336, 2010)
\end{abstract}

\section{-Keywords-}

Dermatofibroma, Lip

\section{INTRODUCTION}

Dermatofibroma (DF), also known as benign fibrous histiocytoma $(\mathrm{BFH})$, is a common benign mesenchymal tumor composed of fibroblastic and histiocytic cells ${ }^{1}$. DF occurs anywhere on the body surface but has a propensity for the extremities. To our knowledge, DF arising in the oral cavity or perioral region is quite rare, and its long-term clinical behavior has yet to be elucidated. Herein we reported the clinical, microscopic, and immunohistochemical aspects of a case of DF of the upper lip.

\section{CASE REPORT}

A 41-year-old female came to our department for

Received June 1, 2009, Revised October 14, 2009, Accepted for publication November 11, 2009

Corresponding author: Seong Jun Seo, M.D., Department of Dermatology, Chung-Ang University Medical Center, 224-1 Heukseokdong, Dongjak-gu, Seoul 156-755, Korea. Tel: 82-2-6299-1525, Fax: 82-2-823-1049, E-mail: drseo@hanafos.com evaluation of a hard nodule on her upper lip that had been noted 4 months earlier. Her medical and family histories were noncontributory. She denied any history of trauma to the lesion. Clinical examination revealed a rubbery, firm, non-mobile nodule, $1.0 \mathrm{~cm}$ in diameter, on the upper lip (Fig. 1). The appearance of the overlying labial mucosa and skin was normal. There was no pain or tenderness. Excision biopsy was performed, and the specimen was stained with hematoxylin-eosin.

Microscopically, a poorly defined, non-encapsulated, nodular tumor was observed throughout the depth of the dermis. Histological findings showed acanthosis of the epidermis and a poorly defined, non-encapsulated deep dermal tumor (Fig. 2A) composed of fibroblastic spindle cells without atypia and pleomorphism in a storiform pattern, separating the dermal collagen, with a few histiocytes in both the superficial (Fig. 2B) and deep portions of the tumor (Fig. 2C). Immunohistochemical stains for CD34, factor XIIla, CD68 and smooth muscle actin (SMA) were then performed on sections of the tumor. CD34 was negative in fibroblastic spindle tumor

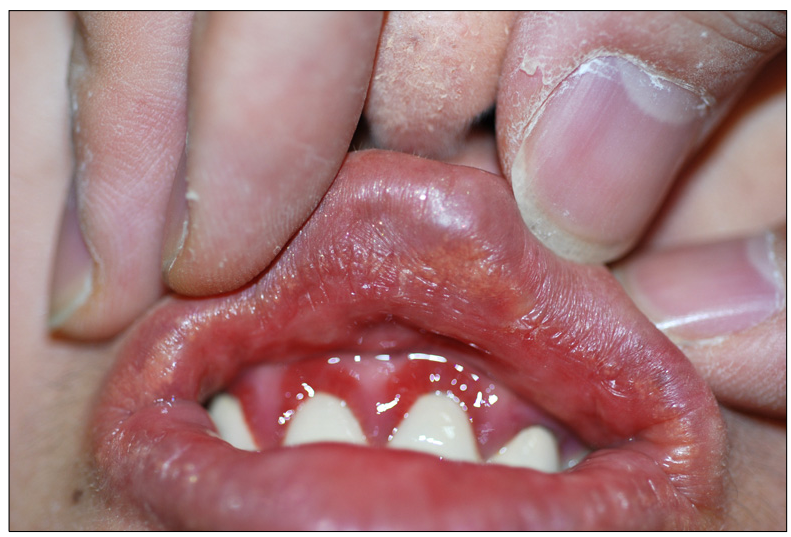

Fig. 1. Rubbery, firm, non-mobile nodule, $1.0 \times 1.0 \mathrm{~cm}$ in diameter, on the upper lip with normal overlying labial mucosa and skin. 

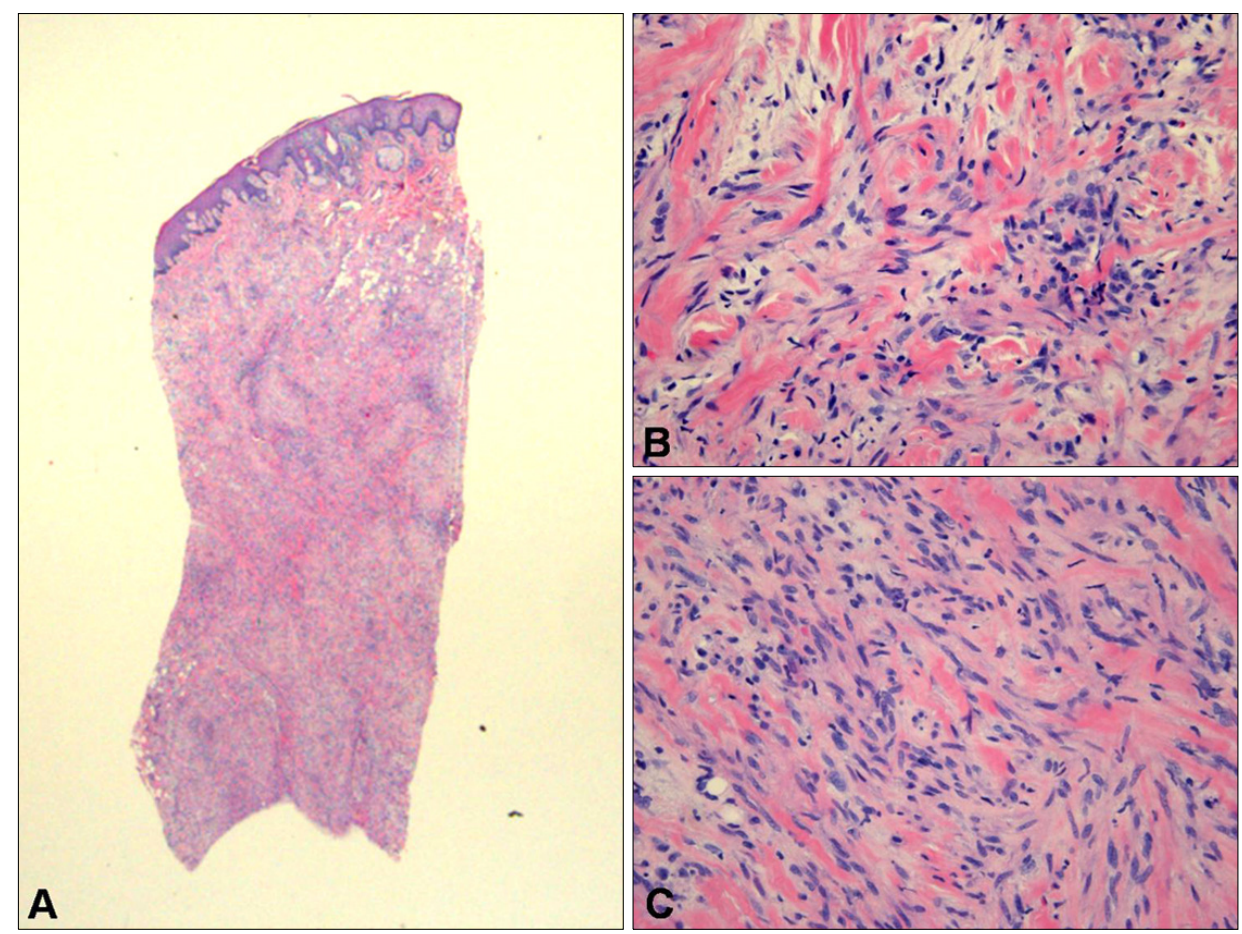

Fig. 2. (A) Histological findings show acanthosis of the epidermis and a poorly defined non-encapsulated deep dermal tumor $(H \& E, \times 20)$. (B, C) The tumor was found to be composed of fibroblastic spindle cells in a storiform pattern, separating dermal collagen with a few histiocytes both in the superficial (B) and deep portions of the tumor (C) (H\&E, $\times 200)$. cells and positive in vessels (Fig. 3A), factor XIIla was positive in only a few dendritic cells and negative in fibroblastic cells (Fig. 3B), CD68 was weak in spindle cells and strong in histiocytes (Fig. 3C), and SMA was strong in fibroblastic spindle cells (Fig. 3D). As a result of clinical and pathologic findings, the diagnosis was interpreted as DF.

\section{DISCUSSION}

DF is a common benign dermal fibrohistiocytic tumor that presents as a firm, red-brown nodule. There has been controversy about the pathogenesis of DF. Whether DF is a true neoplasm or reactive hyperplasia induced by mechanical stimuli is still unclear ${ }^{2}$. Prolonged sun exposure, traumatic injury and chronic infection have been suggested as possible causative agents. DF occurs anywhere on the body surface, most commonly on the extremities, and usually on the lower legs. Involvement of the oral mucosa is quite rare. There have been a few published reports of DF that involved the oral and maxillofacial regions ${ }^{3-7}$. Gray et al. ${ }^{6}$ reviewed the literature on oral and perioral DF and reported that the buccal mucosa/vestibular region was the most commonly affected site. Also, cases of DF/BFH of the tongue, gingiva, mandible, maxilla, lower and upper lip have been described. Yamada et al. ${ }^{7}$ reported a case of BFH of the upper lip in an infant. Five cases of DF of the lip have been reported in the literature (Table 1) $)^{3,5-7}$.

Histologically, the epidermis demonstrates hyperplasia, hyperpigmentation of the basal layer, and elongation of the rete ridges ("dirty fingernail" sign), which are separated by a clear (Grenz) zone from the tumor in the dermis. The tumor itself is composed of fibroblast-like spindle cells, histiocytes, and blood vessels in varying portions.

DF has a variable immunohistochemical profile. Early lesions are highly reactive for macrophage markers such as $C D 68^{8}$. Most cells in early phase DFs have been found to react with factor XIIla, a marker of normal dermal dendrocytes. This reactivity is mostly seen at the periphery of the tumor, continuously diminishes with aging of the lesion, and is completely absent in atrophic variants ${ }^{9}$. Other variably expressed markers include smooth muscle actin, CD56, and NSE. Labeling for SMA is most prominently seen in myofibroblastic $\mathrm{DF}^{10}$. Variable reactivity is seen with vascular markers such as factor VIII or CD31. Exceptional cases with characteristic histologic features of DF show diffuse reactivity for CD $34^{11}$; other rare cases express S-100 protein. Mentzel et al. ${ }^{12}$ reported that tumor cells of facial DF showed immunoreactivity for factor XIIla in 13 out of 17 cases and a focal immunepositivity for CD68 in 6 out of 10 cases; Mentzel et al. ${ }^{12}$ also showed that spindle-shaped tumor cells in 16 out of 19 neoplasms stained at least focally positive for SMA. The more cellular forms of DF tend to express SMA, 

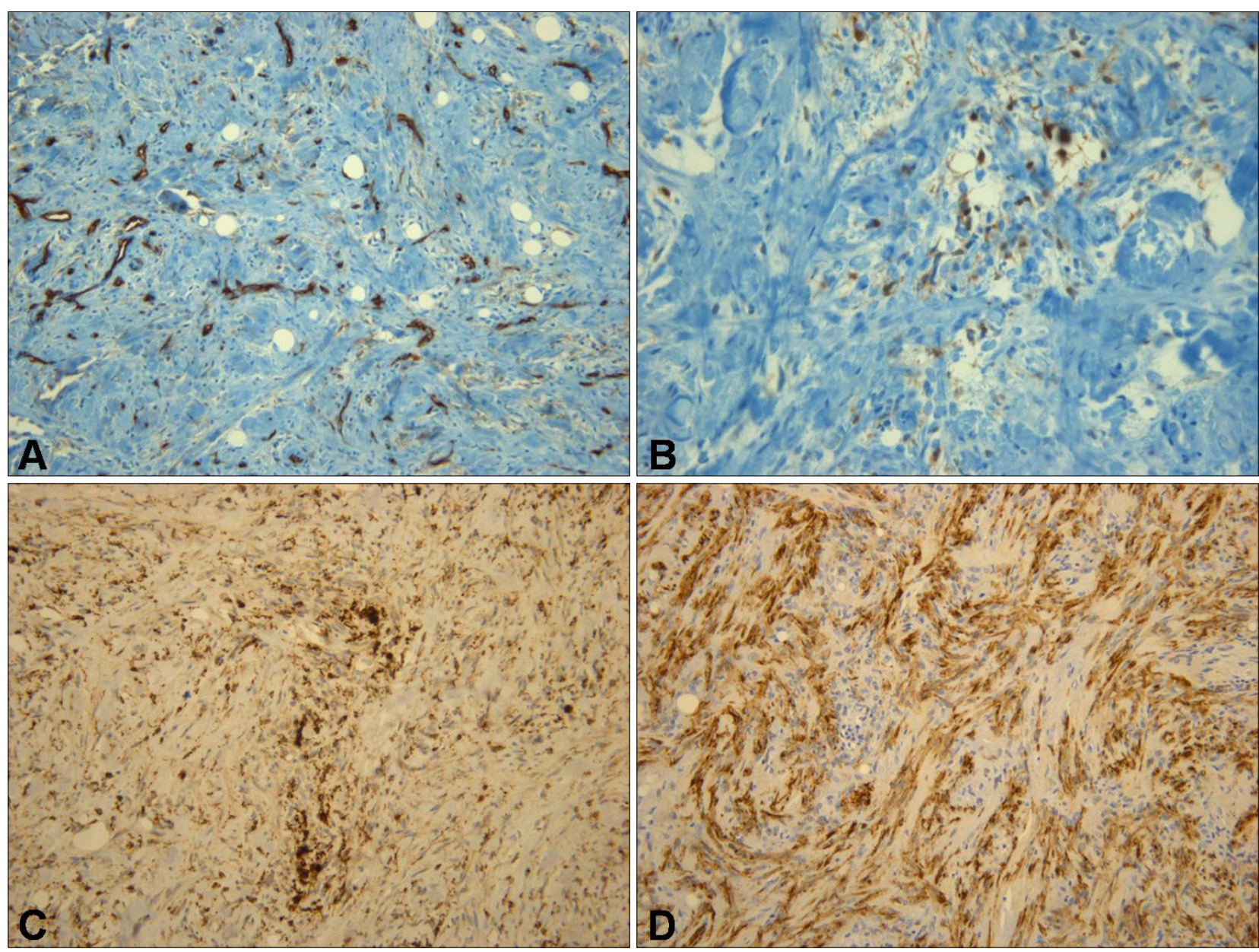

Fig. 3. (A) CD34 was negative in fibroblastic spindle cells and positive in vessels $(\times 200)$. (B) Factor XIIla was positive in only a few dendritic cells and negative in fibroblastic cells $(\times 200)$. (C) CD68 was weak in spindle cells and strong in histiocytes $(\times 200)$. (D) Smooth muscle actin $(S M A)$ was strong in fibroblastic spindle cells $(\times 200)$.

Table 1. Summary of 6 cases of benign fibrous histiocytoma of the lip reported in the literature

\begin{tabular}{|c|c|c|c|c|c|c|c|c|}
\hline Patient No. & Age & Sex & History & Location & Size $(\mathrm{mm})$ & Treatment & Date & Reference \\
\hline 1 & $52 \mathrm{yr}$ & $M$ & None & Lower lip & $5 \times 10$ & Excision & 1975 & Hillis and Beasley ${ }^{3}$ \\
\hline 2 & $22 \mathrm{yr}$ & $\mathrm{F}$ & Trauma & Lower lip & 20 & Excision & 1992 & MacLeod and Jones ${ }^{5}$ \\
\hline 3 & $45 \mathrm{yr}$ & $M$ & None & Upper lip & $20 \sim 30$ & Excision & 1992 & Gray et al. ${ }^{6}$ \\
\hline 4 & $45 \mathrm{yr}$ & $\mathrm{F}$ & Unknown & Lower lip & Unknown & Excision & 1992 & Gray et al. ${ }^{6}$ \\
\hline 5 & $6 \mathrm{mo}$ & M & None & Upper lip & 15 & Excision & 2002 & 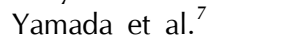 \\
\hline 6 & $41 \mathrm{yr}$ & $\mathrm{F}$ & None & Upper lip & $10 \times 10$ & Excision & 2008 & Present case \\
\hline
\end{tabular}

whereas the lesions with more epithelioid cells and giant cells tend to express histiocytic markers.

The main differential diagnoses of spindle cell neoplasms arising on the face, especially the oral cavity, include nodular fasciitis, low-grade myofibroblastic sarcoma, and neurofibroma. Nodular fasciitis may also present as spindle cells ordered in a storiform configuration, similar to that seen in DF, but the fascicles are separated by a myxoid stroma, mitoses are frequent and immunohisto- chemical staining for S-100 antigen is reactive ${ }^{13}$. Lowgrade myofibroblastic sarcoma is characterized morphologically by ill-defined fascicles of atypical, spindle-shaped myofibroblastic tumor cells that infiltrate preexisting structures in a diffuse pattern. Spindle-shaped tumor cells of DF do not stain positively for desmin, a marker that is frequently expressed in cases of low-grade myofibroblastic sarcoma $^{14}$. Neurofibroma is composed of elongated spindle-shaped S-100 protein-positive tumor cells contain- 
ing fusiform nuclei ${ }^{15}$. Cellular fibrous histiocytoma, the cellular variant of DF, must be especially distinguished from dermatofibrosarcoma protuberans (DFSP). DFSP is generally characterized by more uniform spindle cells and a more prominent storiform pattern than that seen in DF. CD34 staining is usually diffusely positive in DFSP and negative in most forms of DF. However, some DFs may express CD34, and some DFSP may express factor XIIla ${ }^{16}$. Paradoxically, cellular atypia is often more pronounced in cellular fibrous histiocytoma than in DFSP, and factor XIIla staining is often negative.

DFs arising on the face, including the oral cavity, are more often of the cellular type, extend into the subcutaneous fat or muscle, and frequently recur ${ }^{12}$. Therefore, a wider initial excision is recommended, and local excision is the definitive treatment for DF of the head and neck region. Because oral DFs are rare and the long-term clinical behavior has yet to be elucidated, regular clinical follow-up is recommended.

\section{REFERENCES}

1. Calonje E, Mentzel T, Fletcher CD. Cellular benign fibrous histiocytoma. Clinicopathologic analysis of 74 cases of a distinctive variant of cutaneous fibrous histiocytoma with frequent recurrence. Am J Surg Pathol 1994;18:668-676.

2. Calonje E. Is cutaneous benign fibrous histiocytoma (dermatofibroma) a reactive inflammatory process or a neoplasm? Histopathology 2000;37:278-280.

3. Hillis RE, Beasley JD 3rd. Fibrous histiocytoma of the lip: report of a case. J Oral Med 1975;30:81-83.

4. Hoffman S, Martinez MG Jr. Fibrous histiocytomas of the oral mucosa. Oral Surg Oral Med Oral Pathol 1981;52:277-
283.

5. MacLeod SP, Jones JL. Fibrous histiocytoma of the lip secondary to trauma: report of a case. J Oral Maxillofac Surg 1992;50:1091-1093.

6. Gray PB, Miller AS, Loftus MJ. Benign fibrous histiocytoma of the oral/perioral regions: report of a case and review of 17 additional cases. J Oral Maxillofac Surg 1992;50:1239-1242.

7. Yamada $H$, Ishii $H$, Kondoh $T$, Seto $K$. A case of benign fibrous histiocytoma of the upper lip in a 6-month-old infant. J Oral Maxillofac Surg 2002;60:451-454.

8. Senear FE, Caro MR. Histiocytoma cutis. Arch Derm Syphilol 1936;33:209-226.

9. Nestle FO, Nickoloff BJ, Burg G. Dermatofibroma: an abortive immunoreactive process mediated by dermal dendritic cells? Dermatology 1995; 190:265-268.

10. Zelger BW, Zelger BG, Rappersberger K. Prominent myofibroblastic differentiation. A pitfall in the diagnosis of dermatofibroma. Am J Dermatopathol 1997;19:138-146.

11. Zelger B. It's a dermatofibroma, CD34 is irrelevant! Am J Dermatopathol 2002;24:453-454.

12. Mentzel $T$, Kutzner $H$, Rütten $A$, Hügel $H$. Benign fibrous histiocytoma (dermatofibroma) of the face: clinicopathologic and immunohistochemical study of 34 cases associated with an aggressive clinical course. Am J Dermatopathol 2001;23: 419-426.

13. Shlomi B, Mintz S, Jossiphov J, Horovitz I. Immunohistochemical analysis of a case of intraoral nodular fasciitis. J Oral Maxillofac Surg 1994;52:323-326.

14. Beer M, Eckert F, Schmöckel C. The atrophic dermatofibroma. J Am Acad Dermatol 1991;25:1081-1082.

15. Regezi JA, Zarbo RJ, Tomich CE, Lloyd RV, Courtney RM, Crissman JD. Immunoprofile of benign and malignant fibrohistiocytic tumors. J Oral Pathol 1987;16:260-265.

16. Goldblum JR, Tuthill RJ. CD34 and factor-XIIla immunoreactivity in dermatofibrosarcoma protuberans and dermatofibroma. Am J Dermatopathol 1997;19:147-153. 